\title{
Study of bacterial contamination of raw meat in Hyderabad
}

\begin{abstract}
An attempt was made to isolate bacteria from fresh and unprocessed meat products from various butcher shops across the city and identify them. Bacterial colonies were isolated from 100 meat samples including fish and poultry meat. The bacteria isolated from them were identified by using phenotypic, biochemical and molecular characterization. The fidelity of the contamination does not depend only on the microbial quantity but also on the physical factors such as handling of the meat products. As per the findings, to keep up a trust on the food we consume, making sure that there is no taint via bacterial cross contamination in meat and meat products, we need to have strict handling methods. To avoid defiling of products there should be strict quality control checks at slaughterhouses, markets, and butchers should be aware of cleanliness and techniques behind it and the sterilization methods. Meat was found to be more contaminated than eggs. Eggs only need to be washed and sterilized and stored in bacterial resistant packaging. We observed $44 \%$ Enterococcus fecalis, $40 \%$ Klebsiella oxytoca, E. coli $10 \%$, Pseudomonad as mirabilis $4 \%$ and some unidentified bacteria in meat samples.
\end{abstract}

Volume 7 Issue | - 2018

\author{
Vignesh Nagarajan,' Ahmed Wahab, ${ }^{2}$ Smita \\ Shivraj, ${ }^{3}$ Livy Alex ${ }^{4}$ \\ 'Amrita School of Biotechnology, Kerala \\ ${ }^{2}$ Department of Microbiology, Osmania University, India \\ ${ }^{3}$ College of Technology, Osmania University, India \\ ${ }^{4} \mathrm{SLS}$ Cell Cure Technologies Pvt Ltd, India
}

Correspondence: Livy Alex, PhD, SLS Cell Cure Technologies Pvt Ltd, India, Email drlivys@yahoo.com

Received: January 16, 2018 | Published: February 08, 2018

Keywords: IMVIC, E.coli, salmonella, PCR, biochemical, identification, beef, fish, mutton, E. fecalis, integrated disease surveillance programme

\section{Introduction}

Food-borne pathogens are a major source of illness and death thus leading to a huge expenditure of money on healthcare. Generally children are affected the most by food poisoning due to their weak immune systems. Key contributing factors include changes in eating habits, mass catering, availability of street foods at neighborhood corners, social or religious fairs, complex and lengthy food supply procedures with increased international movement and poor hygiene practices. Contaminated raw meat causes $90 \%$ of food-borne illnesses. ${ }^{1,2}$ Proteins are the building blocks of our body. Animal tissue, skeletal muscle and associated fats are consumed as food which is otherwise called meat. It has large amount of proteins which are beneficial for our body. ${ }^{3}$ Demand for meat and its products has increased over the years due to the rise in demand of protein rich food, and aping of the western culture and is preferred over plant proteins.

Cross contamination occurs during the handling of raw meat, especially poultry meat, because of the presence of more liquid in raw meat than cooked meat. ${ }^{4,5}$ Contamination is a common process seen all over the world on carcasses in abattoirs. ${ }^{6,7}$ Drug resistant bacteria can and do travel on meat. ${ }^{8}$ They can also lead to longer illness and more hospitalizations with longer stays. Multi drug resistant infections are on the rise while the development of new antibiotics is coming to a standstill. Various meat samples have been taken from supermarkets in 2011, detailed analysis were performed by U.S Department of agriculture, centers for disease control and prevention, and federal food and drug administration. It was observed that significant amounts of superbug versions of campylobacter and salmonella ${ }^{9}$ were found which leads to 3.6 million food poisoning cases annually. ${ }^{10-13}$ Recent data put out by the Union Health Ministry's Integrated Disease Surveillance Programme (IDSP) has recently made their data public, which indicates that food poisoning is one of the most common outbreaks of India reported in 2017 (Figure 1).

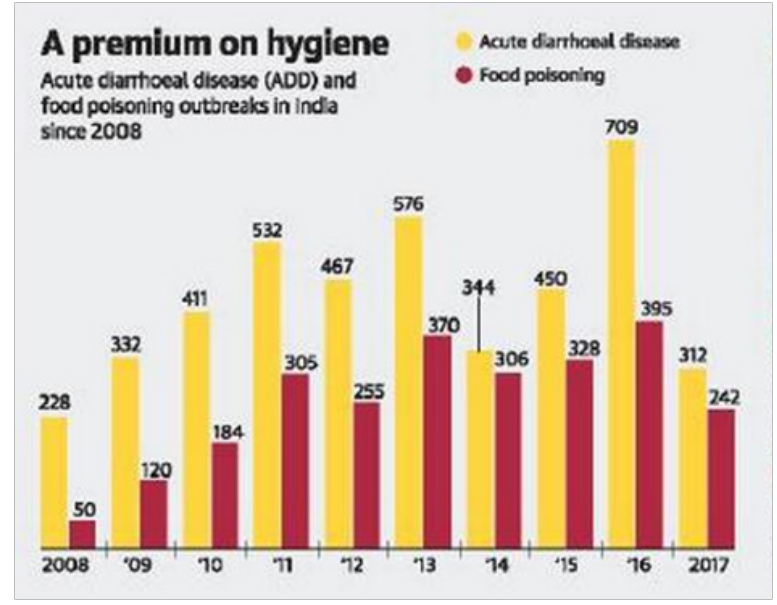

Figure I Incidence of food poisoning.

Our aim here was to enumerate the bacteria sampled from various sources of meat procured from different poultry breeders and slaughter houses $^{14}$ in Hyderabad, and determines the most predominant pathogenic species found in meat.

\section{Materials and methods}

\section{Sample collection}

100 meat samples were collected from butcher shops from areas like Moula Ali, A.S Rao Nagar, Malkajgiri, Tarnaka etc. The samples were collected from chicken, beef, mutton, eggs and fish. The samples were collected from parts like breast of chicken, and thighs of goat $\&$ cow. The egg yolk and fish with scales was used in the study. Processing was done in sterile conditions in our microbiology laboratory for all collected samples. 


\section{Chemicals}

Crystal violet, grams iodine, ethanol, saffranin was used for morphological identification. The reagents and media used for the study were procured from Himedia Company, India such as Nutrient agar, Nutrient Broth, Eosin-Methylene Blue agar, Blood agar, Salmonella-Shigella agar, Thiosulfate-Citrate-Bile Salt-Sucrose agar, Mannitol Salt agar, McConkey agar Voges Proskauer and Methyl red.

Total bacterial count: The total bacterial count was performed on all the samples by Lazy Susan plating method in triplicate on solid Nutrient agar plates after 10 fold serial dilution of samples. The seeded plates were sealed and incubated at $37^{\circ} \mathrm{C}$. The colony forming units were counted after 24hours and expressed in CFU/mg.

Isolation of pathogens: Isolation and identification of bacterial pathogens were carried out based on their growth pattern and colony characteristics on selective and differential media. In addition, grams staining, IMViC, Catalase, Oxidase, urease and motility tests were carried out according to the standard test procedures to confirm the findings. ${ }^{15,16}$

Morphological characterization: grams staining and Motility test were carried out for the gram positive or negative and motile or non motile bacteria respectively. Culture media, Liquid culture media and Enriched media were used as basal media. For biochemical characterization we used Citrate Agar Media, LB-agar media, LB broth media and Tryptone Broth.

Bio chemical characterization: Catalase, Phenyl alanine deamination, Nitrate reduction, $\mathrm{H}^{2} \mathrm{~S}$ production, Citrate utilization, Voges proskaeurs, Methyl red, Indole tests were conducted for biochemical studies.

Catalase test: A bacterial colony was picked up with a toothpick or a platinum loop and mixed with a drop of hydrogen peroxide $(10 \%$ $\mathrm{v} / \mathrm{v}$ in water) taken on a glass slide. The effervescence indicates the presence of the catalase enzyme.

Indole test: Glucose Peptone broth was inoculated with the test organism and incubated at $37^{\circ} \mathrm{C}$ for $24-48 \mathrm{~h}$ and $0.5 \mathrm{~mL}$ of Kovac's reagent was added and gently agitated. A red ring on the top indicated positive reaction.

MR test: Using sterile technique, each experimental organism was inoculated into its appropriately labeled tubes of medium by means of an inoculation loop. The last tube served as a control. All cultures were incubated for 24 to $48 \mathrm{hrs}$, at $37^{\circ} \mathrm{C}$. After 24 hours of incubation 2 to 3 drops of MR reagent was added. A positive reaction was indicated by red color.

VP test: Using sterile technique, each experimental organism was inoculated into its appropriately labeled tubes of medium by means of an inoculation loop. The last tube served as a control. All cultures were incubated for 24 to $48 \mathrm{hrs}$, at $37^{\circ} \mathrm{C}$. After $24 \mathrm{hrs}$ incubation, 1 to 2 drops of Barrett's a reagent was added to each tube and change in color observed.

Triple sugar iron agar test: Using sterile technique, each sample was inoculated into its appropriately labeled tube by means of a stab and streak inoculation. The last tube served as control. The tubes were incubated for 18 to $24 \mathrm{hrs}$ at $37^{\circ} \mathrm{C}$.

\section{Results}

\section{Isolation of bacteria from the meat samples}

5 grams of each meat sample was homogenized and suspended in TSB broth and incubated overnight at $37^{\circ} \mathrm{C}$. Each sample was named as $\mathrm{S}_{1}-\mathrm{S}_{\mathrm{n}}$. Next day, the samples were diluted 10 fold and $5^{\text {th }}$ dilution and $6^{\text {th }}$ dilution samples were placed on LB agar to get isolated colonies. Isolated colonies from each sample was picked and streaked on new plate which had grids and each colony was numbered. This plate was called the master plate.

\section{Preparation of master plate}

Master plates on LB Agar was made by streaking each pure colony on gridded plates and stored at $40 \mathrm{c}$.Each time master plate was subcultured for carrying out various tests.

\section{Morphological identification}

Each of the isolated colonies on the master plate was identified by grams staining and motility experiment. The results are compiled in Table 1. The biochemically characterized isolates were identified based on Bergeys Manual of Determinative Bacteriology.

\section{Biochemical identification}

IMVIC tests were done as mentioned in methods and the results are compiled in Tables 1-6.

Table I Results of the microbial loads in chicken gizzard

\begin{tabular}{|c|c|c|c|c|c|c|c|c|}
\hline \multirow{2}{*}{ Sample } & \multicolumn{6}{|c|}{ Biochemical tests } & \multirow{2}{*}{ Organism } & \multirow{2}{*}{ Gram reaction \& morphology } \\
\hline & Indole & VP & MR & Citrate & Catalase & TSI & & \\
\hline SI (Chicken Gizzard) & $(+)$ & $(-)$ & $(-)$ & $(+)$ & $(+)$ & $(-)$ & E. fecalis & Gram+Cocci \\
\hline 2 & $(+)$ & $(-)$ & $(+)$ & $(+)$ & $(-)$ & $(-)$ & Providencia.sps & U.I* \\
\hline 3 & $(+)$ & $(-)$ & $(-)$ & $(+)$ & $(-)$ & $(-)$ & E. fecalis & Gram+Cocci \\
\hline 4 & $(+)$ & $(-)$ & $(-)$ & $(+)$ & $(+)$ & $(-)$ & E. fecalis & Gram+Cocci \\
\hline 5 & $(+)$ & $(-)$ & $(-)$ & $(+)$ & $(+)$ & $(-)$ & E. fecalis & Gram+Cocci \\
\hline 6 & $(+)$ & $(-)$ & $(-)$ & $(+)$ & $(+)$ & $(-)$ & E. fecalis & Gram+Cocci \\
\hline 7 & $(+)$ & $(-)$ & $(-)$ & $(+)$ & $(+)$ & $(-)$ & E. fecalis & Gram+Cocci \\
\hline 8 & $(+)$ & $(-)$ & $(-)$ & $(+)$ & $(+)$ & $(-)$ & E. fecalis & Gram+Cocci \\
\hline 9 & $(+)$ & $(-)$ & $(-)$ & $(+)$ & $(+)$ & $(-)$ & E. fecalis & Gram+Cocci \\
\hline 10 & $(+)$ & $(-)$ & $(-)$ & $(+)$ & $(+)$ & $(-)$ & E. fecalis & Gram+Cocci \\
\hline
\end{tabular}

*Ul-unidentified 
Table 2 Results of microbial loads in chicken thigh

\begin{tabular}{|c|c|c|c|c|c|c|c|c|}
\hline \multirow{2}{*}{ Sample } & \multicolumn{6}{|c|}{ Biochemical tests } & \multirow{2}{*}{ Organism } & \multirow{2}{*}{ Gram reaction \& morphology } \\
\hline & Indole & VP & MR & Citrate & Catalase & TSI & & \\
\hline S2 (Chicken Thigh) & $(+)$ & $(+)$ & $(-)$ & $(+)$ & $(+)$ & $(-)$ & K. oxytoca & Gram Negative Rods \\
\hline 2 & $(+)$ & $(-)$ & $(-)$ & $(-)$ & $(+)$ & $(-)$ & E. fecalis & \\
\hline 3 & $(-)$ & $(-)$ & $(-)$ & $(+)$ & $(+)$ & $(-)$ & Proteus maribilis & Gram Negative Rods \\
\hline 4 & $(+)$ & $(-)$ & $(-)$ & $(+)$ & $(+)$ & $(-)$ & E. fecalis & Gram Positive Cocci \\
\hline 5 & $(+)$ & $(+)$ & $(-)$ & $(+)$ & $(+)$ & $(-)$ & E. fecalis & Gram Negative Rods \\
\hline 6 & $(+)$ & $(-)$ & $(-)$ & $(-)$ & $(+)$ & $(-)$ & E. fecalis & Gram Positive Cocci \\
\hline 7 & $(+)$ & $(-)$ & $(-)$ & $(-)$ & $(+)$ & $(-)$ & E. fecalis & Gram Positive Cocci \\
\hline 8 & $(+)$ & +1 & $(-)$ & $(+)$ & $(+)$ & $(-)$ & K. oxytoca & Gram Negative Rods \\
\hline 9 & $(+)$ & +1 & $(-)$ & $(+)$ & $(+)$ & $(-)$ & K. oxytoca & Gram Negative Rods \\
\hline 10 & $(+)$ & $(-)$ & $(+)$ & $(-)$ & $(+)$ & $(-)$ & E. coli & Gram Negative Rods \\
\hline
\end{tabular}

Table 3 Results of microbial loads in chicken breast

\begin{tabular}{|c|c|c|c|c|c|c|c|c|}
\hline \multirow{2}{*}{ Sample } & \multicolumn{6}{|c|}{ Biochemical tests } & \multirow{2}{*}{ Organism } & \multirow{2}{*}{ Gram Reaction \& Morphology } \\
\hline & Indole & VP & MR & Citrate & Catalase & TSI & & \\
\hline S3(Chicken Breast) & $(+)$ & $(-)$ & $(-)$ & $(-)$ & $(+)$ & $(-)$ & E. fecalis & Gram Positive Cocci \\
\hline 2 & $(+)$ & $(-)$ & $(+)$ & $(-)$ & $(+)$ & $(-)$ & E. coli & Gram Negative Rods \\
\hline 3 & $(+)$ & $(-)$ & $(-)$ & $(-)$ & $(+)$ & $(-)$ & E. fecalis & Gram Positive Cocci \\
\hline 4 & $(+)$ & $(+)$ & $(-)$ & $(+)$ & $(+)$ & $(-)$ & K. oxytoca & Gram Negative Rods \\
\hline 5 & $(+)$ & $(-)$ & $(+)$ & $(-)$ & $(+)$ & $(-)$ & E. coli & Gram Negative Rods \\
\hline 6 & $(+)$ & $(-)$ & $(-)$ & $(+)$ & $(+)$ & $(-)$ & E. fecalis & Gram Positive Cocci \\
\hline 7 & $(+)$ & $(-)$ & $(-)$ & $(-)$ & $(+)$ & $(-)$ & E. fecalis & Gram Positive Cocci \\
\hline 8 & $(+)$ & $(-)$ & $(-)$ & $(-)$ & $(+)$ & $(-)$ & E. fecalis & Gram Positive Cocci \\
\hline 9 & $(+)$ & $(+)$ & $(-)$ & $(+)$ & $(+)$ & $(-)$ & K. oxytoca & Gram Negative Rods \\
\hline 10 & $(+)$ & $(-)$ & $(-)$ & $(-)$ & $(+)$ & $(-)$ & E. fecalis & Gram Negative Rods \\
\hline
\end{tabular}

Table 4 Results of microbial loads in beef

\begin{tabular}{|c|c|c|c|c|c|c|c|c|}
\hline \multirow{2}{*}{ Sample } & \multicolumn{6}{|c|}{ Biochemical tests } & \multirow{2}{*}{ Organism } & \multirow{2}{*}{ Gram reaction \& morphology } \\
\hline & Indole & VP & MR & Citrate & Catalase & TSI & & \\
\hline S4 (Beef) & $(+)$ & $(+)$ & $(-)$ & $(+)$ & $(+)$ & $(-)$ & K. oxytoca & Gram Negative Rods \\
\hline 2 & $(+)$ & $(-)$ & $(+)$ & $(+)$ & $(+)$ & $(-)$ & U.I & \\
\hline 3 & $(+)$ & $(+)$ & $(-)$ & $(+)$ & $(+)$ & $(-)$ & K. oxytoca & Gram Positive Cocci \\
\hline 4 & $(+)$ & $(-)$ & $(+)$ & $(+)$ & $(+)$ & $(-)$ & U.I & Gram Positive Cocci \\
\hline 5 & $(+)$ & $(-)$ & $(-)$ & $(+)$ & $(+)$ & $(-)$ & E. fecalis & Gram Positive Cocci \\
\hline 6 & $(+)$ & $(+)$ & $(-)$ & $(+)$ & $(+)$ & $(-)$ & K. oxytoca & Gram Negative Rods \\
\hline 7 & $(+)$ & $(+)$ & $(-)$ & $(+)$ & $(+)$ & $(-)$ & K. oxytoca & Gram Negative Rods \\
\hline 8 & $(+)$ & $(-)$ & $(-)$ & $(+)$ & $(+)$ & $(-)$ & E. fecalis & Gram Positive Cocci \\
\hline 9 & $(+)$ & $(-)$ & $(-)$ & $(+)$ & $(+)$ & $(-)$ & E. fecalis & Gram Positive Cocci \\
\hline 10 & $(+)$ & $(+)$ & $(-)$ & $(+)$ & $(+)$ & $(-)$ & K. oxytoca & Gram Negative Rods \\
\hline
\end{tabular}


Table 5 Results of microbial loads in meat (Lamb)

\begin{tabular}{|c|c|c|c|c|c|c|c|c|}
\hline \multirow{2}{*}{ Sample } & \multicolumn{6}{|c|}{ Biochemical tests } & \multirow{2}{*}{ Organism } & \multirow{2}{*}{ Gram reaction \& morphology } \\
\hline & Indole & VP & MR & Citrate & Catalase & TSI & & \\
\hline S5(Meat-Lamb) & $(+)$ & $(+)$ & $(-)$ & $(+)$ & $(+)$ & $(-)$ & K. oxytoca & Gram Negative Rods \\
\hline 2 & $(+)$ & $(+)$ & $(-)$ & $(+)$ & $(+)$ & $(-)$ & K. oxytoca & Gram Negative Rods \\
\hline 3 & $(+)$ & $(+)$ & $(-)$ & $(+)$ & $(+)$ & $(-)$ & K. oxytoca & Gram Negative Rods \\
\hline 4 & $(+)$ & $(-)$ & $(+)$ & $(+)$ & $(-)$ & $(-)$ & Serratia marcesncs & Gram Positive Cocci \\
\hline 5 & $(+)$ & $(+)$ & $(-)$ & $(+)$ & $(+)$ & $(-)$ & K. oxytoca & Gram Negative Rods \\
\hline 6 & $(+)$ & $(-)$ & $(-)$ & $(+)$ & $(+)$ & $(-)$ & E. fecalis & Gram Positive Cocci \\
\hline 7 & $(+)$ & $(+)$ & $(-)$ & $(+)$ & $(+)$ & $(-)$ & K. oxytoca & Gram Negative Rods \\
\hline 8 & $(+)$ & $(+)$ & $(-)$ & $(+)$ & $(+)$ & $(-)$ & K. oxytoca & Gram Negative Rods \\
\hline 9 & $(+)$ & $(-)$ & $(-)$ & $(+)$ & $(+)$ & $(-)$ & E. fecalis & Gram Positive Cocci \\
\hline 10 & $(+)$ & $(+)$ & $(-)$ & $(+)$ & $(+)$ & $(-)$ & K. oxytoca & Gram Negative Rods \\
\hline
\end{tabular}

Table 6 Microbial loads in fish

\begin{tabular}{|c|c|c|c|c|c|c|c|c|}
\hline \multirow{2}{*}{ Sample } & \multicolumn{6}{|c|}{ Biochemical tests } & \multirow{2}{*}{ Organism } & \multirow{2}{*}{ Gram reaction \& morphology } \\
\hline & Indole & VP & MR & Citrate & Catalase & TSI & & \\
\hline S6(Raw Fish) & $(+)$ & $(-)$ & $(+)$ & $(+)$ & $(-)$ & $(-)$ & Serratia marcesncs & Gram Negative Rods \\
\hline 2 & $(+)$ & $(+)$ & $(+)$ & $(-)$ & $(-)$ & $(-)$ & U.I & Gram Negative Rods \\
\hline 3 & $(+)$ & $(-)$ & $(+)$ & $(-)$ & $(+)$ & $(-)$ & Morgenella & Gram Negative Rods \\
\hline 4 & $(+)$ & $(-)$ & $(+)$ & $(+)$ & $(-)$ & $(-)$ & U.I & Gram Positive Cocci \\
\hline 5 & $(+)$ & $(-)$ & $(-)$ & $(-)$ & $(-)$ & $(-)$ & U.I & Gram Negative Rods \\
\hline 6 & $(+)$ & $(-)$ & $(+)$ & $(-)$ & $(-)$ & $(-)$ & Morgenella & Gram Positive Cocci \\
\hline 7 & $(+)$ & $(-)$ & $(+)$ & $(+)$ & $(-)$ & $(-)$ & Serratia marcesans & Gram Negative Rods \\
\hline 8 & $(-)$ & $(-)$ & $(+)$ & $(+)$ & $(-)$ & $(-)$ & Citrobacter & Gram Negative Rods \\
\hline 9 & $(-)$ & $(-)$ & $(-)$ & $(-)$ & $(-)$ & $(-)$ & Clostridium perfringens & Gram Negative Rods \\
\hline 10 & $(+)$ & $(-)$ & $(-)$ & $(-)$ & $(+)$ & $(-)$ & U.I & Gram Negative Rods \\
\hline
\end{tabular}

\section{PCR identification of the most abundant organism}

PCR is a good method which can be used to detect pathogens in such raw meats. ${ }^{17}$ The need of the hour is rapid tests to identify bacteria using molecular methods. According to Farzad et al., ${ }^{18}$ Enterococcus faecalis was the most predominant organism found in their study. Hence it was decided to develop a PCR identification method for $E$. fecalis $^{18}$ (Figures 2-4).

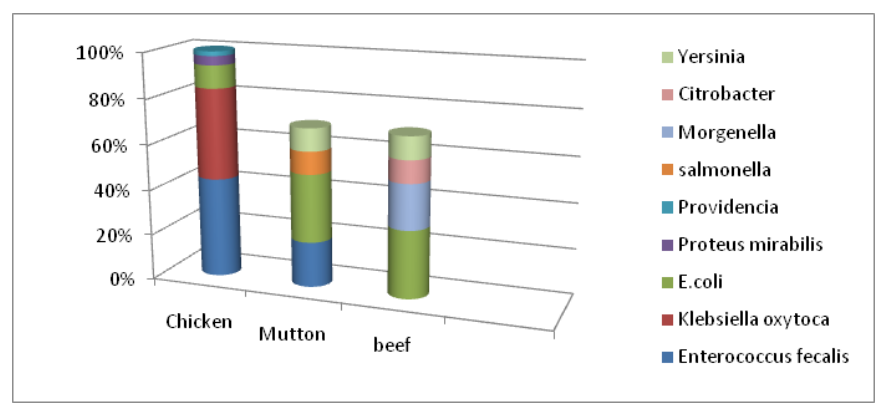

Figure 2 Percentage of bacteria present in various sampled meat.

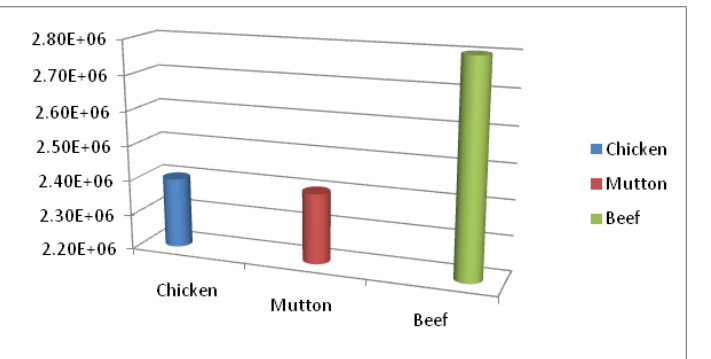

Figure 3 Colony enumeration in different samples, beef being the highest.

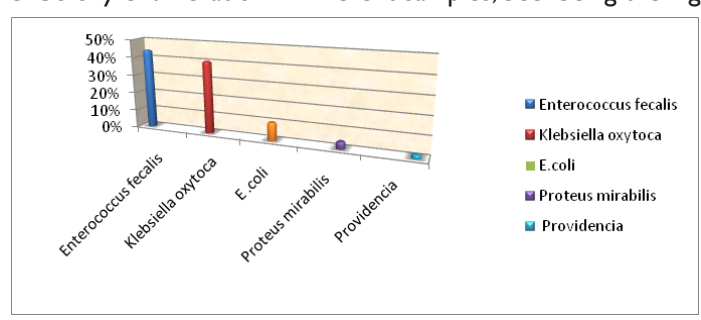

Figure 4 Microbial flora of chicken. 


\section{Discussion}

Food-borne pathogens are the leading cause of illness and death in developing countries costing billions of dollars in medical care and social costs. ${ }^{19}$ Changes in eating habits, mass catering complex and lengthy food supply procedures with increased international movement and poor hygiene practices are major contributing factors.

Contaminated raw meat is one of the main sources of food-borne illness. ${ }^{20}$ Meat is the main edible part of domestic mammals; however, recent definition includes species, such as fish, shellfish, poultry and exotic species such as frogs and alligators. ${ }^{3}$ Similarly, meat refers to animal tissue used as food, mostly skeletal muscles and associated fat but it may also refer to organs including lungs, livers, skin, brains, bone marrow, kidney and a variety of other internal organs as well as blood. Recent increase in the consumption of meat and its products arises from reasons including high protein contents, vitamins, minerals, lipids and savory sensation. ${ }^{3}$

Very few vendors were found to be using refrigerators to store the cut meat. Defective storage temperature for poultry products and prolonged holding at warm temperatures affect microbiological quality and safety of the meat. ${ }^{21,22}$

Meat was being chopped on dirty wooden logs (tree trunks), which are rarely washed and dried in the sun. The butchers are not accustomed to wearing gloves and majority of today's diseases are food borne arising due to contamination by bacteria. Most of us buy meat from local slaughter shops which pose a high risk of contamination. Larger abattoirs have modern cutting and processing machines which are cleaner, but they are mostly for export purposes only. ${ }^{20}$ The magnitude of contamination increases from the time the animals are brought to the slaughter house till it goes to individual houses for consumption. ${ }^{23}$ The inspection of floors, walls, ceilings, drains, overhead lines, platforms, equipment, people, and water and transport vehicles should be done routinely. ${ }^{24}$ Routine inspection of slaughter houses should be made mandatory by local Governments.

\section{E. fecalis}

110 colonies out of 250 samples were E. fecalis. Despite the concern about pathogenicity of enterococci recent studies point out that food and meat enterococci, especially Enterococcus faecalis have much lower pathogenicity potential than clinical strains. They are known for their high tolerance. On the contrary, enterococci have important inference in the diary industry. Enterococci contaminate raw meats in the range of 102-104 CFU per gram and are very resistant to extreme in temperature, $\mathrm{pH}$ and salinity. They multiply to high numbers and act as spoiling agents in processed meats. In order to produce infection, enterococci must be able to colonize host tissues, resist the host's non-specific and immune defense mechanisms and produce pathological changes. Adherence assays have shown that enterococci can attach to intestinal and urinary tract epithelial cells and heart cells by means of adhesions expressed on bacterial surfaces, with regard to colonization of host tissue.

\section{E. coli}

Escherichia coli (E. coli) are bacteria present in intestines of human and animal. Shiga toxin-producing strains of E. coli, or STECs, are responsible for most food-related $E$. coli infections. E. coli $\mathrm{O} 157: \mathrm{H} 7$ and other STECs like E. coli $\mathrm{O} 145$ and E. coli $\mathrm{O} 121: \mathrm{H} 19$ produce a toxin called Shiga toxin, which causes illness in humans. Deer and livestock harbor the bacteria in their intestine. So E.coli does not infect them.

As per CDC report 2011, it is estimated that E. coli infections account for over 2,000 hospitalizations in the United States each year. Contamination of the meat with E. coli $\mathrm{O} 157$ : $\mathrm{H} 7$ happens during the slaughter when the faeces or intestine of the infected animal comes in contact with the carcass. There is a high chance of the mixing of E.coli during tenderization of the meet mechanically than during simply cutting the meat (Figure 5).

The initial symptoms of $E$. coli infection include the sudden onset of cramps and abdominal pain, followed by diarrhea within 24hours. Diarrhea may be watery or bloody. Less common symptoms include fever and chills. If the infected meat is cooked to 160 degree F, then infection can be prevented.

Housewives and cooks in restaurants need to be trained to understand the importance of avoiding allowing raw meats to come into contact with other foods while cooking.

In the study conducted by Sharma $\mathrm{K}$ et al., ${ }^{7}$ the pathogenic microorganisms isolated were E. coli $(98 \%)$, Enterococcus faecalis (90\%), Staphylocoocus aureus (20\%), Staphylococcus epidermidis (20\%), Pseudomonas spp. (10\%), Salmonella spp. (2\%), Bordetella $(1 \%)$. Other organisms that were isolated in this study were Klebsiella pneumoniae (98\%), Enterococcus aerogenes (90\%), Micrococcus spp. (69\%), Citrobacter spp. (52\%), Proteus spp. (50\%), Klebsiellaoxytoca (35\%) and Providencia spp. (22\%).

Our results obtained showed that $\mathrm{E}$. faecalis was the predominant organism in chicken and meat samples while E. coli was the predominant organism in beef. Also E. coli is more prevalent in the samples than Salmonella sp. This is in conformity with a study, who also reported high prevalence of $E$. coli than Salmonella sp. The need of the hour, is increased and improved efforts to develop molecular technologies to detect pathogens earlier in the food processing chain. ${ }^{24,25}$ Techniques to identify drug resistance also need to be integrated with the current technologies to help understand drug resistance and its consequences. ${ }^{9}$ Campylobacter can be spread easily and just a few bacteria could cause illness. ${ }^{11}$ This could come from raw or undercooked chicken, or from contamination due to washing raw chicken. Around $80 \%$ of all the campylobacter infections, are linked to chickens, which carry the organism in their guts and faces. ${ }^{26,27}$ Farmers typically overstock their small sheds with chicks to make profits. During the "thinning" stage campylobacter is often spread from flock to flock. The birds tend to panic and defecate when they are transported, causing further contamination. The bird droppings are the major source of contamination.

Campylobacter can be killed by cooking, but is easily spread from raw meat to other surfaces in the kitchen. ${ }^{28-30}$ Washing raw chicken can spread the campylobacter to taps and worktops. The bacteria are unlikely to cause illness if the meat is cooked properly. To summarize we would like to emphasize the need of food safety training course to meat handlers periodically.

\section{Acknowledgements}

None.

\section{Conflict of interest}

The author declares no conflict of interest. 


\section{References}

1. Arul KT, Saravanan S. Assessment of contamination in chicken meat by food- borne Staphylococcus aureus. Intl J Res Pure and Appl Microbiol. 2011;1:59-60.

2. Barbudhe B, Swain BK, Chakurkar EB, et al. Microbial quality of poultry meat with special reference to Listeria monocytogenes. Indian $J$ Poult Sci. 2003;38(3):305-307.

3. Nakai S, Modler WH. Food protein. 1st ed. USA: Wiley-VCH Inc; 2000. p. $128-133$.

4. Darshana B, Bhaisare et al. Bacterial Pathogens in Chicken Meat. International Journal of Life Sciences Research. 2014;2(3):1-7.

5. Javadi A, Saeid S. Microbial profile of marketed broiler meat. MiddleEast. J Sci Res. 2011;9(5):652-656.

6. Kumar HTS, Pal UK, Rao VK, et al. Effects of processing on the physicchemical, Microbiological and sensory quality of fresh chicken meat. Int J Meat Sci. 2012;2:1-6.

7. Keshab Prasad Sharma. Assessment of Microbial load of raw meat Samples sold in the Open Markets of city of Kolkata. IOSR Journal of Agriculture and Veterinary Science. 2015;8(3):24-27.

8. Maripandi A, Al-Salamah A. Multiple-Antibiotic resistance and plasmid profiles of Salmonella enteritidis isolated from retail chicken meats. Am J Food Technol. 2010;5(4):260-268.

9. Duffy G, Cloak OM, Osullivan MG, et al. The incidence and antibiotic resistance profiles of Salmonella spp. on Irish retail meat products. Food Microbiol. 1999;16(6):623-631.

10. Nielsen M, Engberg J, Madsen M. Distribution of serotypes of Campylobacter jejuni and C. coli from Danish patients, poultry, cattle and swine. FEMS Immunol Med Microbiol. 1997;19(1):47-56.

11. Naik G, Jayaraj YM. Campylobacter jejuni diarrhea in north Karnataka Indian Pediatrics. 1998;35(8):768- 770

12. Rahimi E, Tajbakhsh E. Prevalence of campylobacter species in poultry Meat in the esfahan city, Iran. Bulg J Vet Med. 2008;11(4):257-262.

13. Kornelija G, Damir K, Uhitil S, et al. Determination of Campylobacter spp. in poultry slaughterhouses and poultry meat. Vet arhiv. 2009;79:491497

14. Das K, Biswas S. Effects of slaughtering methods on microbiologica quality of chicken. $J$ Vet Pub Health. 2003;101:147-152.

15. Holt JG, Krieg NR, Sneath PHA, et al. Bergey's Manual of Determinative Bacteriology. 9th ed. USA: Williams and Williams Baltimore; 1994. 566

16. APHA. Compendium of methods for the microbiological examination of foods. 2nd ed. USA: American Public Health Association; 1984.
17. Ruban SW, Thyageeswaran M, Sharadha R. Isolation and identification of Salmonella spp from retail chicken meat by polymerase chain reaction. Intl J Micro Res. 2010;1(3):106-109.

18. Farzad Sayyadifar. Molecular identification of bacteria isolated from meat sample. International Journal of Applied Biology and Pharmaceutical Technology. 2012;3:34-39.

19. Fratamico PM, Bhunia AK, Smith JL. Foodborne pathogens in Microbiology and Molecular Biology. UK: Caister Academic press; 2005. p. 270-275.

20. Bhandare SG, Sherikarv AT, Paturkar AM, et al. A comparison of microbial contamination of sheep/goat carcasses in a modern Indian abattoir and traditional meat shops. Food Contr. 2007;18(7):854-868.

21. Mepba HD, Achinewhu SC, Aso SN, et al. Microbiological quality of selected street foods in Port Harcourt, Nigeria. Journal of Food Safety. 2007;27(2):208-218

22. Prakash, Perumal P, Jegadeesh KD, et al. Molecular characterization of plasmid mediated esbl resistant Salmonella isolated from poultry environment in Namakkal district (India). Adv Biotech. 2012;12:2.

23. Mead C. Hygiene Problems and Control of Process Contamination. Processing of poultry. USA: Elsevier Science Publishers Ltd; 1989. p. $183-220$

24. Das K, Biswas S. Effects of slaughtering methods on microbiological quality of chicken. $J$ Vet Pub Health. 2003;101:147-152.

25. Soad A Abdullah, Laila A Al-Shatti, Ali F Alhajraf, et al. The detection of foodborne bacteria on beef: the application of the electronic nose. Springer Plus. 2013;2:687.

26. Bandekar JR, Raut AD, Kapadnis BP. Occurrence of Campylobacter in local poultry meat in Pune and Mumbai. Founder's Day Special Issue. 2005:120-123.

27. Berrang E, Buhr RJ, Cason JA. Campylobacter recovery from external and internal organs of commercial broiler carcass prior to scalding. Poult Sci. 2000;79(2):286-290.

28. Daoud JR. Microbial quality of frozen chicken meat at grocery stores in qena city. International Conference and Exhibition on Food Processing \& Technology, 2012.

29. Iroha IR, Ugbo EC, Ilang DC, et al. Bacteria contamination of raw meat sold in Abakaliki. Journal of Public Health and Epidemiology. 2011;3(2):49-53.

30. Rabie S, Khalifa NO, Radwan ME. et al. Epidemiological and Molecular Studies of Salmonella Isolates from Chicken, Chicken Meat and Human in Toukh, Egypt. Global Veterinaria. 2012;8(2):128-132. 